\title{
ABM versus GECON: uma Análise Comparativa
}

\author{
Luiz Carlos Miranda \\ Cláudio de Araújo Wanderley \\ Juliana Matos de Meira
}

\section{Resumo}

O objetivo do trabalho é realizar um estudo comparativo entre os modelos de Gestão Baseada em Atividades (ABM) e o de Sistema de Informação de Gestão Econômica (GECON). O trabalho procurará apontar os pontos semelhantes e identificar as diferenças relevantes entre esses dois modelos gerenciais. A principal semelhança entre o GECON e o ABM está relacionada à busca da melhoria dos processos internos por meio do gerenciamento das atividades. Com relação às divergências, verifica-se que o ABM está mais voltado para a cadeia de valor, enquanto que a preocupação do GECON é apurar o lucro econômico por meio da definição de uma serie de critérios de avaliação dos aspectos financeiros, contábeis e econômicos, que dão suporte ao seu modelo de mensuração. O trabalho também apresenta um estudo de caso aplicado em uma empresa prestadora de serviços, revelando os pontos convergentes e divergentes dos dois modelos.

Palavras-chaves: controladoria; sistemas de informações gerenciais; medição de desempenho organizacional; ABM; GECON.

\section{Abstract}

The purpose of this paper is to do a comparative study between Activity Based Management $(\mathrm{ABM})$ and Information System of Economic Management (GECON). In this paper we try to indicate important similarities and differences between both models of management. The main similarity between GECON and ABM is related with searching improvement of internal process, by the managing activities. About the differences, it is possible to observe that the ABM takes more care with the supply chain, while GECON is worried about calculating the economic profit, by defining several criterions of valuation of the economic, accountant and financial aspects, which support its management model. In this paper, we also present a case study applied in a service company, showing the similarities and the differences between both models.

Key words: controllership; managerial information systems; performance measurement; ABM; GECON. 


\section{INTRODUÇÃO}

A constante evolução tecnológica e social que tem permitido a atuação das grandes empresas em nível mundial, juntamente com a nova ordem política e econômica que está induzido, até mesmo de maneira involuntária, os países a abrirem suas fronteiras, vêm gerando uma verdadeira guerra pelos mercados consumidores. Como decorrência, para garantir a sobrevivência nesse novo cenário, as empresas estão repensando suas formas de administrar e de controlar seus negócios.

Um dos fatores-chaves para garantir a sobrevivência nesse novo ambiente é a definição de sistemas de informações mais eficientes, que permitam às organizações gerir eficientemente e competitivamente suas atividades. Na era do conhecimento, quem possui informação superior obtém vantagens competitivas em relação aos concorrentes que possuam sistemas de informações menos eficientes.

É esse contexto que explica o surgimento de diversos modelos de mensuração de desempenho, com o propósito de gerenciar eficientemente as informações corporativas que dão suporte à tomada de decisões. $\mathrm{O}$ trabalho foi motivado por essa situação, na qual tais modelos desempenham papel relevante na sobrevivência e sucesso das organizações. Um grande número de empresas está na busca incessante por tais sistemas, gerando assim a necessidade de maiores estudos sobre sistemas de informações gerenciais e, mais especificamente, daqueles que gerenciam as informações econômico-financeiras ou que tenham impacto sobre a sua situação econômico-financeira.

O objetivo do trabalho é realizar um estudo comparativo entre dois modelos de gerenciamento: o de Gestão Baseada em Atividades (Activity Based Management - ABM), desenvolvido nos Estados Unidos na década de 90 e difundido mundialmente a partir dos trabalhos de Kaplan e Cooper; e o de Sistema de Informação de Gestão Econômica (GECON), desenvolvido no Brasil a partir dos estudos de Catelli e Guerreiro, da Universidade de São Paulo. O trabalho procurará apontar as semelhanças e divergências relevantes entre esses dois modelos gerenciais.

A metodologia utilizada no trabalho é a da revisão bibliográfica embasada em consulta a livros, teses, dissertações, revistas e sites da Internet, que abordam temas relacionados com os objetivos da pesquisa. Além disso, é apresentado um 
exemplo prático em uma empresa de serviço de contabilidade utilizando ferramentas do ABM e do GECON, para identificar a viabilidade econômicofinanceira de um cliente ${ }^{(1)}$.

\section{Sistema de Informação de Gestão Econômica (GECON)}

O Sistema de Informação de Gestão Econômica (GECON) foi desenvolvido por um grupo de pesquisadores liderado pelo Professor Catelli, que criou uma linha de pesquisa no Departamento de Contabilidade e Atuária da Faculdade de Economia, Administração e Contabilidade da Universidade de São Paulo, no final dos anos 70. De acordo com Catelli (1999, p.31), “o GECON significa administração por resultado, tendo como objetivo a otimização dos resultados por meio da melhoria da produtividade e de eficiência operacionais”. Este autor também enfatiza que o escopo do GECON é inteiramente voltado para a eficácia empresarial, cuja concretização se verifica pela otimização do resultado econômico. Na concepção de Catelli e Guerreiro (1994, p.1), “o GECON é estruturado dentro de uma concepção 'holística' e compreende a integração dos seguintes elementos: modelo de gestão[...]; modelo de decisão[...]; modelo de mensuração do resultado [...]; modelo de informação [...]”.

Estes elementos do GECON serão explicados com mais detalhes a seguir.

\section{Modelo de Gestão}

O modelo de gestão busca identificar os conceitos relativos aos procedimentos de administração de uma entidade. Conforme Catelli (1999), gestão é um processo que visa a tomada de decisões para a operacionalização de um negócio. O processo de administração compreende o planejamento, execução e controle. A definição do modelo GECON começa com a descrição de um conjunto básico de proposições, usadas pelo modelo de gestão, e assim especificadas por Guerreiro (1989):

. deve haver planejamento estratégico;

. deve haver planejamento operacional;

. deve haver controle das atividades. Catelli e Guerreiro (1994, p. 8) definem atividade como o "processo físico-operacional que consome recursos e gera serviços e produtos, demandando a ocorrência de um ou mais eventos"; 
- a garantia da continuidade da empresa só é obtida quando as atividades realizadas geram um resultado líquido no mínimo suficiente para assegurar a reposição de todos os ativos consumidos no processo de realização de tais atividades. O lucro é a medida de eficácia da empresa; o lucro global é resultante das decisões setoriais tomadas pelos responsáveis das diversas áreas;

. devem ser atribuídos às áreas custos e receitas sobre os quais tenham efetivo controle;

. a gestão deve contemplar os aspectos operacionais, econômicos e financeiros dos eventos;

. os resultados devem evidenciar, separadamente, as contribuições das gestões operacional e financeira de cada área;

. a mensuração das transações deve ser efetuada com a utilização de conceitos econômicos;

. aos recursos e produtos/serviços das diversas atividades devem ser atribuídos, respectivamente, custos e receitas com base em valor de mercado.

\section{Modelo de Decisão}

O modelo de decisão do GECON tem as seguintes diretrizes básicas, de acordo com Parisi e Nobre (apud Catelli, 1999):

. deve incorporar os aspectos comportamentais estabelecidos pelas crenças e valores do subsistema institucional da empresa, caracterizados e definidos no modelo de gestão, devendo estes prevalecer sobre os aspectos comportamentais individuais dos gestores;

. o lucro econômico é visto como a melhor medida da eficácia empresarial, sendo que o desempenho dos gestores é avaliado pelo resultado econômico que atinge em relação ao previamente estabelecido. Da mesma forma "o desempenho da empresa em relação ao lugar em que estava e aonde pretendia chegar é medido pelo resultado econômico";

- o modelo de decisão deve ser único, devendo ter como pressuposto o método do custeio variável, apurar a margem de contribuição em função dos aspectos econômicos e financeiros dos eventos e em conformidade com o processo físico/operacional, e estar harmonizado com a missão de cada atividade da empresa e com a missão da empresa como um todo; 
- deve ser utilizada uma metodologia normativa que explore o comportamento da empresa, em vez de estudar detidamente os processos mentais dos administradores.

\section{Modelo de Mensuração}

O modelo de mensuração do GECON é aquele que dá suporte para a determinação do lucro econômico, principal medida de desempenho empresarial do sistema. Segundo Guerreiro (1989), a determinação do lucro econômico deve se pautar pelos seguintes princípios básicos:

. os ativos devem ser avaliados pelo potencial de benefício futuro que geram para a empresa;

. a variação do poder aquisitivo da moeda deve ser considerada;

- a depreciação dos ativos imobilizados representa a perda do potencial na geração de serviços. Esta perda será a diferença entre o valor dos serviços no início e no final de um período;

- o lucro como diferença do montante de riqueza em dois momentos distintos de tempo deve, portanto, incorporar os ganhos e perdas decorrentes das valorizações e desvalorizações dos ativos que a empresa possui;

- o patrimônio líquido deve representar o valor atual mínimo da empresa;

- os resultados das atividades são obtidos por meio da utilização dos conceitos de preço de transferência, custo de oportunidade e avaliação pelo preço de mercado;

- o preço de transferência é utilizado para demonstrar a receita que uma atividade realiza, por ter gerado bens/serviços para outra. É o valor a ser pago por uma atividade, por receber produtos/serviços de outra atividade;

. o preço de transferência é mensurado pelo preço de mercado à vista;

. a receita é reconhecida quando ocorre um acréscimo do valor dos bens, isto é, agregação de valor. Neste contexto, todas as atividades geram receitas, que serão mensuradas pelo valor de mercado na condição de pagamento à vista;

. os custos e despesas realizados para gerar as receitas serão mensurados pelos valores praticados na condição de pagamento à vista;

- é utilizado o conceito de custeio direto, com a finalidade de medir a margem de contribuição das atividades na margem global da empresa; 
- finalmente, deve ser reconhecido o goodwill da empresa. O valor do goodwill corresponderá à diferença entre o valor presente dos fluxos de benefícios futuros produzidos pela empresa (valor econômico global) e o valor da soma dos valores econômicos individuais dos ativos da empresa.

\section{Modelo de Informação}

O modelo de informação do GECON, de acordo com Libonati (1996, p. 98), "expõe as características das informações a serem processadas e apresentadas pelo sistema de informação. Neste sentido, modelo de informação é influenciado pelos modelos de gestão, de decisão e de mensuração. A partir do funcionamento do sistema de informação, os papéis são invertidos, ou seja, a informação é que influencia a tomada de decisões”.

Guerreiro (1989) elenca as características das informações que devem compor o modelo de informação do GECON.

. Adequação à decisão, oportunidade, precisão, relevância e objetividade.

- Valor econômico: seu benefício deve ser superior ao custo de geração da informação.

. Relatividade: a informação sobre um dado deve possuir relação com outro de mesma natureza.

. Exceção: a informação deve comunicar as ocorrências que não estavam preestabelecidas.

. Entendimento: as informações devem ser facilmente compreensíveis pelo usuário.

- Acionabilidade: a informação deve ser dirigida aos gestores que efetivamente influenciam a ação ou possuem o poder de decisão.

- Motivação: a informação deve motivar os tomadores de decisão a otimizarem o resultado global.

. Consistência e integração.

. Uniformidade de critérios.

- Indicar causas: a informação deve indicar as causas das variações entre o resultado planejado e ocorrido.

. Volume: a quantidade deve ser compatível no auxílio à tomada de decisão. 
- Seletividade: as informações devem ser previamente selecionadas, visando a atender às necessidades específicas dos gestores.

- Generalidade: as informações contidas no sistema de informação devem atender a um grande número de usuários, sem que seja necessária nenhuma modificação fundamental no sistema.

. Flexibilidade.

. Tempo de resposta: as informações solicitadas devem ser atendidas rapidamente.

\section{Activity Based Management (ABM)}

Nos primeiros anos da década de 90, o conceito de Gerenciamento Baseado em Atividades (ABM) começa a tomar força e a se propagar pelo mundo dos negócios. Há três pontos de vista principais sobre a relação entre ABC e ABM. Um deles é o argumento levantado por Raffish e Turney (1991), definindo o ABC como um "subproduto do ABM", embora historicamente o ABM tenha surgido após o ABC. Num segundo ponto de vista, afirma-se que o ABC é necessário ao $A B M$, e é nisso que o $A B C$ tem valor; em outras palavras, o $A B C$ e o $A B M$ são mais eficazes somente quando estão intimamente ligados. Outros autores consideram o $\mathrm{ABC}$ e o $\mathrm{ABM}$ complementares: o $\mathrm{ABM}$ não pode ser adotado eficazmente sem o $\mathrm{ABC}$, e o $\mathrm{ABC}$, por si só, não traz benefícios à organização.

Entre essas várias visões, optamos pela de Maskell (1996). Segundo este autor, o ABM foi uma evolução natural do ABC. Com a implantação do ABC, os contadores gerenciais, pela primeira vez, passaram a ter grande conhecimento dos processos da organização e dos custos a eles associados (Maskell, 1996). Essa é também a opinião de Sakurai (1997, p.97), segundo o qual "a finalidade principal do ABC é proporcionar aos administradores informações sobre custo do produto, para a análise de lucratividade e outras decisões. O ABM objetiva o gerenciamento das atividades, para aperfeiçoamento do processo de produção e inovação".

OABM utiliza como principal fonte de informação a análise baseada em atividade, ou seja, o principal sistema de informação do ABM é o ABC. Para se implementar um gerenciamento baseado em atividades, primordialmente, é preciso já ter sido implementado o ABC na empresa. Neste sentido Kaplan e Cooper (1998) apontam que o $\mathrm{ABC}$ levou naturalmente ao Gerenciamento Baseado na Atividade, que se configura como um conjunto de medidas interligadas, que só podem ser tomadas 
com base em informações provenientes de sistemas de custeio baseados na atividade. O ABM permite que a empresa atinja seus objetivos com menos recursos. O ABM atinge seus objetivos por meio de duas aplicações complementares: o ABM operacional e o ABM estratégico. A Figura 1 sintetiza as idéias do ABM.

\section{Figura 1: ABM Operacional versus ABM Estratégico}

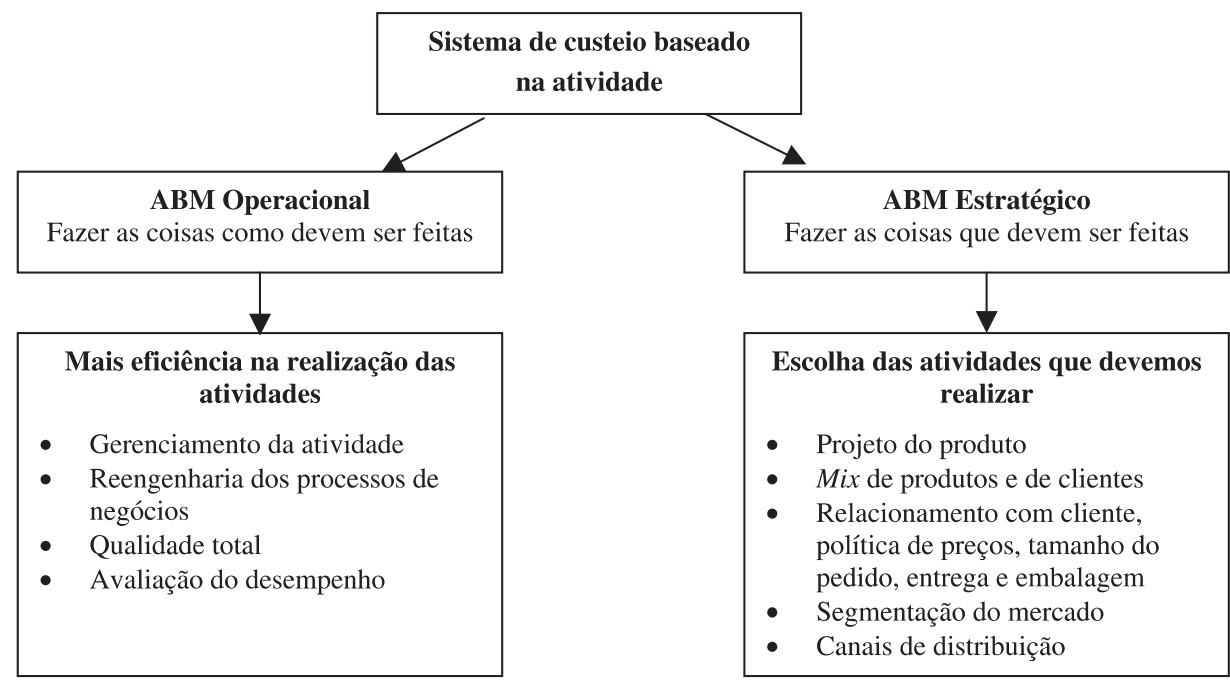

Fonte: Kaplan e Cooper (1998, p.15).

Maskell (1996) define o ABM como a tecnologia associada ao uso de valiosa informação, advinda do entendimento dos processos e respectivos custos, para a melhoria das operações. É por meio do ABM que os processos são analisados, para que se entendam as atividades e as tarefas nelas incluídas. Esse conhecimento gera oportunidades para a melhoria dos processos. Segundo este autor, “ABM é:

- um veículo para a criação de melhoria dos processos, sendo tanto benfícios contínuos e incrementais como reestruturações radicais da organização da empresa;

. um modelo para mostrar como custos (e receitas) são criados por meio dos processos e atividades. Se as atividades são entendidas, então seus custos são entendidos. Se os processos são entendidos, então o negócio é entendido;

. uma ferramenta que integra o pessoal da contabilidade e o pessoal das operações por meio da busca pela melhoria; e 
- a base para outros métodos contábeis avançados como o custo-meta, orçamento baseado em atividades e análise de lucratividade” (Maskell, 1996, p.106).

Maskell (1996) cita alguns exemplos de métodos empregados por empresas para ampliar o uso do ABM. Entre esses métodos, o autor destaca:

. uso da análise baseada na atividade como padrão da metodologia de suporte à decisão;

- reorganização da empresa, de maneira que os gerentes sejam responsáveis pelos processos, ao invés de responsáveis pelos departamentos;

- uso do custo-meta baseado na atividade nas fases de desenho do produto e processo de desenvolvimento;

. análise de rentabilidade do cliente baseada na atividade;

. ampliação da análise do ABM aos clientes, fornecedores e outros parceiros, de modo que os benefícios do processo de melhoria estendam-se além das fronteiras legais da companhia;

- desenvolvimento de medidas de desempenho e critérios de repartição dos ganhos baseados nas atividades e nos objetivos de melhoria das atividades.

\section{Estudo Comparativo entre o ABM e o GeCon}

O ABM e o GECON são sistemas eminentemente gerenciais, ou seja, o enfoque de ambos é a geração de informações úteis para o processo decisório do gestor interno da empresa. Esses dois sistemas não estão preocupados em atender às exigências legais impostas para a geração de relatórios aos usuários externos à empresa.

Ambos têm como foco de análise a atividade. Os dois modelos buscam gerenciar os processos que consomem os recursos organizacionais para melhorar o desempenho da empresa como um todo.

Para o GECON a atividade constitui-se como um centro de lucro, pois são alocados custos, despesas e receitas, com o objetivo de encontrar o seu resultado econômico, que é composto pela margem operacional, margem financeira e custos fixos identificados. Aqui também não há discordância, pois o ABM também pode medir o resultado da atividade. Maskell (1996) afirma que o ABM é um modelo para apresentar como custos e receitas são criados.

O método de custeio aplicado no GECON é o direto, que só aloca às unidades 
de acumulação os custos diretamente identificados com a atividade. Os custos fixos são considerados como gastos estruturais e do período, não havendo rateio dos gastos indiretos. Para o ABM o método de custeio utilizado é o da absorção por meio do ABC (Custeio Baseado em Atividades).

Quanto ao enfoque, há concordância entre o GECON e o ABM. Embora o GECON enfatize mais o aspecto operacional, o lado estratégico fica evidenciado quando seus proponentes mencionam o planejamento. Isto fica evidente na afirmação de Catelli (1999, p.30): “o sistema de gestão no modelo GECON diz respeito ao processo de planejamento, execução e controle operacional das atividades e é estruturado com base na missão da empresa, em suas crenças e valores, em sua filosofia administrativa e num processo de planejamento estratégico [...] Uma preocupação básica do sistema é espelhar em termos econômicofinanceiros o que ocorre nas atividades operacionais da empresa”.

O enfoque do ABM é o gerenciamento das atividades internas e da cadeia de valor (fornecedores, canais de distribuição e clientes) que é considerado, respectivamente, no ABM operacional e no ABM estratégico (Kaplan e Cooper, 1998).

Os objetos de acumulações principais do GECON são as atividades e os produtos/ serviços. O ABM contempla objetos mais amplos: atividades, produtos/serviços, clientes, fornecedores e canais de distribuição. Ambos os modelos utilizam o conceito de orçamento baseado em atividades como instrumento de controle e planejamento da empresa. Além disso, o orçamento é um instrumento de simulação dos cenários futuros para a busca da otimização do desempenho organizacional (Guerreiro, 1989; Cooper e Kaplan, 1997).

Quanto à mensuração, o GECON tem por premissa que o resultado econômico é a melhor medida da eficácia empresarial. Já o ABM propõe a utilização de múltiplos indicadores, tanto financeiros como não financeiros, além de poder ser integrado com o Balanced Scorecard, sistema de medição de desempenho proposto por Kaplan e Norton (1997). Dessa divergência surge uma outra: o sistema de medição de desempenho do GECON é predominantemente baseado em medidas financeiras, enquanto que o do ABM é baseado em medidas financeiras e não-financeiras.

Quanto à avaliação do ativo, o modelo GECON define que os ativos devem ser avaliados pelo potencial de benefício futuro que geram para a empresa, ou seja, o fluxo de benefícios futuros validados pelo mercado, pelo valor presente. Para o ABM a avaliação do ativo é uma decisão tomada pelo contador da empresa de forma independente do modelo; porém recomenda-se a utilização do custo corrente como forma de sua mensuração (Guerreiro, 1989; Kaplan e Cooper, 1998; Catelli, 1999). 
Quanto à depreciação, o GECON a trata como uma perda do potencial na geração de serviços. Esta perda será a diferença entre o valor dos serviços no início e no final do período. Para o ABM a depreciação é análoga à recuperação do componente principal de um empréstimo, no pagamento mensal de um bem, refletindo o retorno do capital (Guerreiro, 1989; Kaplan e Cooper, 1998).

No tocante ao preço de transferência, o modelo GECON o utiliza para obter o valor a ser pago por uma atividade, por receber produtos/serviços de outra atividade. O preço de transferência no GECON é mensurado pelo preço do produto/serviço no mercado à vista (Guerreiro, 1989; Catelli, 1999). Para o ABM o preço de transferência é utilizado para obter o valor a ser pago por uma unidade da empresa por receber produtos/serviços de outra unidade. O preço de transferência no ABM é mensurado pelo preço de mercado dos produtos/serviços transferidos. Porém, caso estas informações não estejam disponíveis, deverá ser utilizado o custeio baseado em atividades (Cooper e Kaplan, 1997).

No tocante ao lucro, os dois sistemas se assemelham. O GECON utiliza o lucro econômico, que representa a diferença de riqueza em dois momentos distintos de tempo, ou seja, o lucro representa o incremento de riqueza da empresa. As premissas necessárias para a obtenção do resultado econômico são tratadas no modelo de mensuração do GECON. Já o ABM, conforme Kaplan e Cooper (1998), utiliza o conceito do Valor Econômico Agregado (EVA), cuja fórmula, segundo Ehrbar (1999), é o lucro operacional líquido no período menos o custo total do capital investido ou menos a taxa de ganho que os investidores poderiam obter se fizessem outra aplicações com o mesmo risco (Stewart, 1991).

O modelo GECON estabelece que a receita deve ser reconhecida quando ocorre um acréscimo do valor dos bens, ou seja, agregação de valor. O reconhecimento da receita no ABM ocorre quando a empresa executa uma atividade (Guerreiro, 1989; Kaplan e Cooper, 1998; Catelli, 1999).

Quanto ao reconhecimento do goodwill, o modelo GECON estabelece que o seu valor corresponderá à diferença entre o valor presente dos fluxos de benefícios futuros produzidos pela empresa e o montante da soma dos valores econômicos individuais dos ativos da empresa. O reconhecimento do goodwill não é tratado no modelo ABM (Guerreiro, 1989; Kaplan e Cooper, 1998; Catelli, 1999).

A preocupação com o aspecto financeiro fica evidente no GECON, que trata com grande detalhe a utilização de alguns conceitos contábeis como mensuração do patrimônio líquido e utilização da correção monetária. O ABM dá bem menos ênfase ao aspecto financeiro, preocupando-se com o entendimento dos processos e com a sua melhoria. 
A seguir é apresentado quadro com resumo das comparações entre o Sistema de Informação de Gestão Econômica e o Activity Based Management (ABM).

\section{Quadro 1: Resumo das Comparações entre o ABM e o GECON}

\begin{tabular}{|c|c|c|c|}
\hline Item Comparado & GECON & ABM & Comparação* \\
\hline $\begin{array}{l}\text { Tipo de sistema } \\
\text { (usuário alvo) }\end{array}$ & $\begin{array}{l}\text { Sistema gerencial } \\
\text { (gestor) }\end{array}$ & $\begin{array}{l}\text { Sistema gerencial } \\
\text { (gestor) }\end{array}$ & $\sqrt{ }$ \\
\hline Foco & Atividade & Atividade & $\sqrt{ }$ \\
\hline $\begin{array}{l}\text { Tratamento da } \\
\text { atividade }\end{array}$ & Centro de resultado & Centro de resultado & $\sqrt{ }$ \\
\hline Método de custeio & Custeio direto & Custeio por absorção (ABC) & $\mathbf{X}$ \\
\hline Enfoque do sistema & $\begin{array}{l}\text { Estratégico (planejamento) e } \\
\text { operacional (execução e controle } \\
\text { operacional das atividades). } \\
\text { Mais ênfase no operacional. }\end{array}$ & $\begin{array}{l}\text { Estratégico (análise de valor e } \\
\text { fazer as coisas que devem ser } \\
\text { feitas) e operacional (fazer as } \\
\text { coisas como devem ser feitas). }\end{array}$ & $\mathbf{x} \sqrt{ }$ \\
\hline $\begin{array}{l}\text { Objetos de } \\
\text { acumulação de custos }\end{array}$ & Atividades e produtos/serviços. & $\begin{array}{l}\text { Atividades, produtos/serviços, } \\
\text { fornecedores, clientes e canais } \\
\text { de distribuição. }\end{array}$ & $\mathbf{x} \sqrt{ }$ \\
\hline $\begin{array}{l}\text { Medidas de } \\
\text { desempenho } \\
\text { (foco das medidas) }\end{array}$ & $\begin{array}{l}\text { Resultado econômico é a mais } \\
\text { importante (aspectos } \\
\text { financeiros). }\end{array}$ & $\begin{array}{l}\text { Múltiplos indicadores (aspectos } \\
\text { financeiros e não financeiros). }\end{array}$ & $\mathbf{X}$ \\
\hline $\begin{array}{l}\text { Preocupação com } \\
\text { aspectos financeiros }\end{array}$ & $\begin{array}{l}\text { Grande preocupação. } \\
\text { É o foco principal do sistema de } \\
\text { medição. }\end{array}$ & $\begin{array}{l}\text { Menor preocupação. } \\
\text { Equilíbrio entre medidas } \\
\text { financeiras e não-financeiras. }\end{array}$ & $\mathbf{X}$ \\
\hline Avaliação do ativo & $\begin{array}{l}\text { Pelo potencial de benefícios } \\
\text { futuros. }\end{array}$ & $\begin{array}{l}\text { O critério não é estipulado pelo } \\
\text { modelo, mas recomenda a } \\
\text { utilização do custo corrente. }\end{array}$ & $\mathbf{X}$ \\
\hline Depreciação & $\begin{array}{l}\text { Representa uma perda do } \\
\text { potencial na geração do serviço. } \\
\text { É a diferença entre o valor dos } \\
\text { serviços no início e no final do } \\
\text { período. }\end{array}$ & $\begin{array}{l}\text { É análogo ao repagamento do } \\
\text { componente principal no } \\
\text { pagamento mensal de um bem. }\end{array}$ & $\mathbf{X}$ \\
\hline Preço de transferência & $\begin{array}{l}\text { Utilizado para obter o valor dos } \\
\text { produtos/serviços transferidos } \\
\text { para outra atividade. É medido } \\
\text { pelo preço do produto/serviço no } \\
\text { mercado à vista. }\end{array}$ & $\begin{array}{l}\text { Utilizado para obter o valor dos } \\
\text { produtos/serviços transferidos } \\
\text { para outra unidade da empresa. } \\
\text { É medido pelo preço do } \\
\text { produto/serviço no mercado; } \\
\text { porém se o preço não estiver } \\
\text { disponível no mercado, deverá } \\
\text { utilizar a metodologia do ABC. }\end{array}$ & $\mathbf{x} \sqrt{ }$ \\
\hline Lucro & $\begin{array}{l}\text { Lucro econômico tendo como } \\
\text { base o modelo de mensuração do } \\
\text { GECON. }\end{array}$ & $\begin{array}{l}\text { Valor Econômico Agregado } \\
\text { (EVA). }\end{array}$ & $\begin{array}{c}\sqrt{ } \\
\text { (são conceitos } \\
\text { semelhantes) }\end{array}$ \\
\hline $\begin{array}{l}\text { Reconhecimento da } \\
\text { receita }\end{array}$ & $\begin{array}{l}\text { Quando ocorre um acréscimo no } \\
\text { valor do bem. }\end{array}$ & $\begin{array}{l}\text { Quando a empresa executa uma } \\
\text { atividade. }\end{array}$ & $\mathbf{X}$ \\
\hline Goodwill & $\begin{array}{l}\text { É considerado no modelo de } \\
\text { mensuração do GECON. }\end{array}$ & $\begin{array}{l}\text { Não trata sobre o assunto, pois } \\
\text { o foco não é a medição do } \\
\text { resultado econômico. }\end{array}$ & $\mathbf{X}$ \\
\hline $\begin{array}{l}\text { Outros conceitos } \\
\text { contábeis como } \\
\text { avaliação do } \\
\text { patrimônio líquido e } \\
\text { correção monetária }\end{array}$ & $\begin{array}{l}\text { Esses conceitos são tratados em } \\
\text { detalhe no modelo de } \\
\text { mensuração do GECON. }\end{array}$ & $\begin{array}{l}\text { Não trata sobre o assunto, pois } \\
\text { não tem foco nos aspectos } \\
\text { financeiros. }\end{array}$ & $\mathbf{X}$ \\
\hline
\end{tabular}

Nota: * Significado dos símbolos: $\sqrt{ }$ - convergência entre os dois sistemas.

$\mathbf{X}$ - divergência entre os dois sistemas.

$\mathrm{X} \sqrt{ }$ - convergência parcial entre os dois sistemas. 


\section{Estudo de Caso sobre o ABC/ABM e o GECON}

Nessa seção do trabalho é apresentada a aplicação dos fundamentos teóricos de ambos os sistemas (ABC/ABM e GECON), mediante um exemplo prático que pretende demonstrar a utilização de cada um no ramo da prestação de serviços, permitindo ao leitor observar as suas vantagens e limitações.

Vamos supor que uma empresa que presta serviços de contabilidade deseje conhecer melhor a lucratividade de um cliente (Cliente A), com o qual ela fechou recentemente um contrato por $\$ 6.500,00$. Além dessa receita do Cliente $\mathrm{A}$, a empresa tem receitas de $\$ 30.000$ com outros clientes da empresa prestadora de serviços contábeis.

A empresa de contabilidade possui três atividades: Fiscal, Pessoal e Contabilidade. A atividade fiscal é responsável pelo levantamento e registro dos tributos devidos pelos clientes da empresa. A atividade de pessoal é responsável por calcular e registrar os gastos relativos aos funcionários dos clientes. A atividade de contabilidade recebe os dados das atividades de pessoal e fiscal e, juntamente com outros registros contábeis, processa esses dados, registra-os e gera os relatórios contábeis, além de fazer o atendimento dos clientes.

Para conhecer a lucratividade desse cliente, será aplicada a metodologia do ABC/ABM e, posteriormente, será utilizado o modelo GECON.

A estrutura de custos diretos e indiretos da empresa é apresentada na Tabela 1. A tabela relaciona os gastos diretos por natureza e por atividades. Os custos indiretos estão descritos por natureza, com os respectivos direcionadores de custos por atividade. Esses direcionadores serão utilizados no custeio por atividade, para alocar os custos indiretos às atividades e destas para os clientes. As medidas utilizadas no exemplo estão entre as recomendadas pela literatura do custeio $\mathrm{ABC}$ para direcionar custos às atividades, primeiro estágio de alocação de custos pelo ABC (Cooper e Kaplan, 1998; Atkinson et al., 2000).

Aqui está uma grande diferença entre o ABC e o GECON: enquanto que no primeiro os custos indiretos são distribuídos aos objetos de acumulação (atividades, produtos e clientes são os mais usuais), no GECON o custo da mão-de-obra é considerado fixo e só identificável à área, não sendo apropriado a produtos ou clientes individuais. Para o GECON a utilização dos direcionadores de custos para identificá-los às atividades, no primeiro estágio, e aos produtos e clientes, no segundo estágio, é considerada rateio e, portanto, não deve ser feita. 


\section{Tabela 1: Estrutura de Custos em Relação às Atividades}

\begin{tabular}{|l|c|r|l|}
\hline \multicolumn{1}{|c|}{ CUSTOS } & $\begin{array}{c}\text { QUANT. } \\
\text { FUNC. }\end{array}$ & VALOR (\$) & $\begin{array}{c}\text { DIRECIONADORES DE } \\
\text { CUSTOS P/ ATIVIDADES }\end{array}$ \\
\hline CUSTO DIRETO - CONTAB. & & & \\
\hline Funcionários & 4 & $3.000,00$ & \\
\hline Aluguel de Software & & $1.000,00$ & \\
\hline Soma & & $\mathbf{4 . 0 0 0 , 0 0}$ & \\
\hline CUSTO DIRETO - FISCAL & 2 & $1.000,00$ & \\
\hline Funcionários & & 500,00 & \\
\hline Aluguel de Software & & $\mathbf{1 . 5 0 0 , 0 0}$ & \\
\hline Soma & & & \\
\hline CUSTO DIRETO - PESSOAL & 3 & $1.500,00$ & \\
\hline Funcionários & & 500,00 & \\
\hline Aluguel de Software & & $\mathbf{2 . 0 0 0 , 0 0}$ & \\
\hline Soma & & & \\
\hline CUSTOS INDIRETOS & 2 & $15.000,00$ & Horas de mão-de-obra direta \\
\hline Diretoria & & $1.000,00$ & Horas de mão-de-obra direta \\
\hline Energia & & 700,00 & N $^{\circ}$ de chamadas solicitadas \\
\hline Telefone & & 800,00 & N $^{\circ}$ de requisições solicitadas \\
\hline Material de Expediente & & $1.000,00$ & Área ocupada \\
\hline Aluguel do Escritório & & $1.500,00$ & N $^{\circ}$ de Computadores \\
\hline Depreciação de Computadores & & $\mathbf{2 0 . 0 0 0 , 0 0}$ & \\
\hline Soma & & $\mathbf{2 7 . 5 0 0 , 0 0}$ & \\
\hline TOTAL & & & \\
\hline
\end{tabular}

A seguir mostra-se os passos para a utilização do Custeio ABC, que permitirão o cálculo do custo das atividades e dos clientes. O primeiro passo é fazer um levantamento da quantidade de recursos utilizados pelos direcionadores de custos. A Tabela 2 apresenta a quantidade desses direcionadores, por atividade.

\section{Tabela 2: Direcionadores de Custos para as Atividades}

\begin{tabular}{|l|c|c|c|c|c|}
\hline ATIVIDADE & $\begin{array}{c}\text { HORAS MÃO- } \\
\text { DE-OBRA } \\
\text { DIRETA }\end{array}$ & $\begin{array}{c}\mathrm{N}^{\circ} \text { DE } \\
\text { CHAMADAS } \\
\text { TELEFON. }\end{array}$ & $\begin{array}{c}\mathrm{N}^{\circ} \text { DE } \\
\text { REQUISI- } \\
\text { ÇÕES }\end{array}$ & $\begin{array}{c}\mathrm{N}^{\circ} \text { DE } \\
\text { COMPUTA- } \\
\text { DORES }\end{array}$ & $\begin{array}{c}\text { ÁREA } \\
\text { OCUPADA }\end{array}$ \\
\hline Contabilidade & 640 & 250 & 60 & 4 & $40 \%$ \\
\hline Fiscal & 320 & 150 & 30 & 2 & $30 \%$ \\
\hline Pessoal & 480 & 100 & 50 & 3 & $30 \%$ \\
\hline Total & $\mathbf{1 . 4 4 0}$ & $\mathbf{5 0 0}$ & $\mathbf{1 4 0}$ & $\mathbf{9}$ & $\mathbf{1 0 0 \%}$ \\
\hline
\end{tabular}

A Tabela 3 evidencia como os recursos não identificados diretamente às atividades (custos indiretos da Tabela 1) foram alocados a elas, com a utilização dos direcionadores de custos (vide Tabela 2). A seqüência de cálculo para obter o custo das atividades, tendo como base a alocação dos gastos com a diretoria, foi a seguinte: (1) Custo unitário do direcionador - custos com a diretoria , horas mão-de-obra direta $=\$ 15.000,00,1.440=\$ 10,4166 / \mathrm{hm}$; e (2) Custo da 
atividade - custo unitário do direcionador $\mathrm{x} \mathrm{n}^{\circ}$ de direcionadores da atividade $=$ $\$ 10,4166$ x $640=\$ 6.666,67$ (Contabilidade); \$10,4166 x $320=\$ 3.333,33$ (Fiscal); e $\$ 10,4166$ x $480=\$ 5.000,00$ (Pessoal). O custo das demais atividades foi calculado seguindo-se o mesmo procedimento.

\section{Tabela 3: Custos Indiretos por Atividades}

\begin{tabular}{|l|r|r|r|r|}
\hline \multicolumn{1}{|c|}{ CUSTOS } & CONTABILIDADE & \multicolumn{1}{c|}{ FISCAL } & \multicolumn{1}{c|}{ PESSOAL } & \multicolumn{1}{c|}{ TOTAL } \\
\hline Diretoria & $6.666,67$ & $3.333,33$ & $5.000,00$ & $15.000,00$ \\
\hline Energia & 444,44 & 222,22 & 333,33 & $1.000,00$ \\
\hline Telefone & 350,00 & 210,00 & 140,00 & 700,00 \\
\hline Material de Expediente & 342,86 & 171,43 & 285,71 & 800,00 \\
\hline Aluguel do Escritório & 400,00 & 300,00 & 300,00 & $1.000,00$ \\
\hline Depreciação de Computadores & 666,67 & 333,33 & 500,00 & $1.500,00$ \\
\hline Total & $\mathbf{8 . 8 7 0 , 6 3}$ & $\mathbf{4 . 5 7 0 , 3 2}$ & $\mathbf{6 . 5 5 9 , 0 5}$ & $\mathbf{2 0 . 0 0 0 , 0 0}$ \\
\hline
\end{tabular}

Para obter-se o custo total de cada atividade, soma-se aos custos diretos (vide Tabela 1) os custos indiretos (vide Tabela 3). O resultado é apresentado na Tabela 4.

Tabela 4: Custo Total das Atividades

\begin{tabular}{|l|r|r|r|}
\hline \multicolumn{1}{|c|}{ ATIVIDADES } & \multicolumn{1}{c|}{$\begin{array}{c}\text { CUSTOS } \\
\text { DIRETOS }\end{array}$} & $\begin{array}{c}\text { CUSTOS } \\
\text { INDIRETOS }\end{array}$ & \multicolumn{1}{c|}{ TOTAL } \\
\hline Contabilidade & $4.000,00$ & $8.870,63$ & $12.870,63$ \\
\hline Fiscal & $1.500,00$ & $4.570,32$ & $6.070,32$ \\
\hline Pessoal & $2.000,00$ & $6.559,05$ & $8.559,05$ \\
\hline Total & $\mathbf{7 . 5 0 0 , 0 0}$ & $\mathbf{2 0 . 0 0 0 , 0 0}$ & $\mathbf{2 7 . 5 0 0 , 0 0}$ \\
\hline
\end{tabular}

Como o foco deste exemplo é calcular o custo dos clientes, os custos diretos serão apropriados diretamente ao objeto de custo, ou seja, aos clientes. Assim, os gastos com mão-de-obra direta são alocados diretamente aos clientes, devido à existência de apontamentos que registram o número de horas consumidas por cada cliente em cada atividade. Das Tabelas 1 e 2 obtém-se os dados para o cálculo do valor da hora de mão-de-obra direta. O resultado está na Tabela 5.

Tabela 5: Hora de Mão-de-Obra Direta

\begin{tabular}{|l|c|c|c|}
\hline ATIVIDADES & $\begin{array}{c}\text { Custo Total } \\
\text { da Mão-de-Obra }(\$)\end{array}$ & $\begin{array}{c}\text { Total de horas de } \\
\text { mão-de-obra direta }\end{array}$ & $\begin{array}{c}\text { VALOR } \\
\text { DA HORA }\end{array}$ \\
\hline Contabilidade & $3.000,00$ & 640 & 4,69 \\
\hline Fiscal & $1.000,00$ & 320 & 3,13 \\
\hline Pessoal & $1.500,00$ & 480 & 3,13 \\
\hline \multicolumn{2}{|r}{} & Total & Total \\
\cline { 2 - 4 }
\end{tabular}


Uma vez obtido o valor da hora de mão-de-obra direta, o próximo passo é obter o custo da mão-de-obra do Cliente A. Este é obtido pela multiplicação do número de horas consumidas pelo valor da hora. O resultado está na Tabela 6.

\section{Tabela 6: Mão-de-obra Direta do Cliente A}

\begin{tabular}{|l|c|c|c|}
\hline \multicolumn{1}{|c|}{ ATIVIDADES } & $\begin{array}{c}\text { HORAS CONSUMIDAS } \\
\text { CLIENTE A }\end{array}$ & $\begin{array}{c}\text { VALOR DA HORA } \\
\$ / \mathrm{h}\end{array}$ & $\begin{array}{c}\text { MÃO-DE-OBRA } \\
\text { CLIENTE A (\$) }\end{array}$ \\
\hline Contabilidade & 120 & 4,69 & 562,50 \\
\hline Fiscal & 60 & 3,13 & 187,50 \\
\hline Pessoal & 100 & 3,13 & 312,50 \\
\hline \multicolumn{2}{r|}{} & Total & $\mathbf{1 . 0 6 2 , 5 0}$ \\
\cline { 2 - 3 } & &
\end{tabular}

Além dos custos diretos, deve-se alocar aos clientes os custos indiretos. Os gastos com aluguel do software são diretos em relação à atividade e indiretos em relação aos clientes, pois embora possam ser identificados às atividades, não é possível alocá-los diretamente aos clientes, sendo necessário que eles sejam adicionados aos custos indiretos das atividades e, posteriormente, alocados aos clientes por meio dos direcionadores de atividades. Para calcular o custo o Cliente A, foram adotados os seguintes procedimentos: identificação dos custos das atividades, que, nesse caso, considerou apenas os custos indiretos em relação aos clientes; identificação da quantidade total de direcionadores; identificação do custo unitário do direcionador; identificação da quantidade de direcionadores consumida pelo Cliente A; e identificação do custo (indireto) do cliente por atividade (vide Tabela 7).

\section{Tabela 7: Custos Indiretos do Cliente A por Atividade}

\begin{tabular}{|c|c|c|c|}
\hline & \multicolumn{3}{|c|}{ Atividades } \\
\hline & Contabilidade & Fiscal & Pessoal \\
\hline Custos Indiretos das Atividades & $8.870,63$ & $4.570,32$ & $6.559,05$ \\
\hline Custo do Software & $1.000,00$ & 500,00 & 500,00 \\
\hline Total (a) & $9.870,63$ & $5.070,32$ & $7.059,05$ \\
\hline Direcionadores & $\begin{array}{c}\mathrm{N}^{\circ} \text { de } \\
\text { lançamentos }\end{array}$ & $\begin{array}{c}\mathrm{N}^{\circ} \mathrm{de} \\
\text { lançamentos }\end{array}$ & $\begin{array}{c}\mathrm{N}^{\circ} \text { de } \\
\text { funcionários } \\
\text { dos clientes }\end{array}$ \\
\hline Total de direcionadores $(\mathrm{b})$ & 1.450 & 1.250 & 80 \\
\hline $\begin{array}{l}\text { Valor unitário do direcionador } \\
\text { (a / b) }\end{array}$ & 6,8073 & 4,0563 & 88,2381 \\
\hline $\begin{array}{l}\text { Consumo de atividades do Cliente } \\
\text { A (em número de direcionadores) }\end{array}$ & 450 & 350 & 20 \\
\hline Custo do Cliente A por atividade & $3.063,30$ & $1.419,69$ & $1.764,76$ \\
\hline
\end{tabular}

O custo total do Cliente A será a soma dos custos diretos e indiretos. A Tabela 8 apresenta esse resultado. 
Tabela 8: Custo Total do Cliente A por Atividade

\begin{tabular}{|l|r|r|c|}
\hline ATIVIDADES & CUSTOS DIRETOS & CUSTOS INDIRETOS & TOTAL \\
\hline Contabilidade & 562,50 & $3.063,30$ & $3.625,80$ \\
\hline Fiscal & 187,50 & $1.419,69$ & $1.607,19$ \\
\hline Pessoal & 312,50 & $1.764,76$ & $2.077,26$ \\
\hline Total & $\mathbf{1 . 0 6 2 , 5 0}$ & $\mathbf{6 . 2 4 7 , 7 5}$ & $\mathbf{7 . 3 1 0 , 2 5}$ \\
\hline
\end{tabular}

A Tabela 9 apresenta a demonstração do resultado sob a ótica do ABM, a qual aponta que o Cliente A não é lucrativo, pois está obtendo um resultado negativo de $\$ 810,25$. Já os outros clientes estão gerando um resultado positivo de $\$ 9.810,25$ e, portanto, absorvendo o prejuízo causado com o Cliente A e deixando a empresa com um resultado total de $\$ 9.000,00$.

\section{Tabela 9: Projeção do Resultado - Sistema ABM}

\begin{tabular}{|l|r|r|r|}
\hline \multicolumn{1}{|c|}{ DESCRIÇÃO } & CLIENTE A & OUTROS CLIENTES & \multicolumn{1}{c|}{ TOTAL } \\
\hline Receita de Serviços & $6.500,00$ & $30.000,00$ & $36.500,00$ \\
\hline Custos Diretos & $(1.062,50)$ & $(4.437,50)$ & $(5.500,00)$ \\
\hline Custos Indiretos & $(6.247,75)$ & $(15.752,25)$ & $(22.000,00)$ \\
\hline Resultado & $\mathbf{( 8 1 0 , 2 5 )}$ & $\mathbf{9 . 8 1 0 , 2 5}$ & $\mathbf{9 . 0 0 0 , 0 0}$ \\
\hline
\end{tabular}

Agora será feita à análise utilizando a metodologia do GECON. O primeiro passo é estabelecer o preço de transferência que as áreas vão utilizar para cobrar serviços umas das outras. Neste exemplo, será necessário definir o preço que as áreas Fiscal e de Pessoal irão cobrar da área da Contabilidade pelos serviços prestados ao Cliente A. Supondo que exista condições de verificar tal preço no mercado, o preço que utilizaremos será o menor preço no mercado à vista da atividade Fiscal e de Pessoal, que é de \$400,00 e \$500,00, respectivamente. Esses valores representam os preços de transferências dessas atividades e serão repassados posteriormente para a atividade de contabilidade.

Embora se saiba que os proponentes do GECON são contrários à distribuição dos custos de mão-de-obra direta aos produtos e clientes, apenas para efeitos didáticos consideramos o custo da mão-de-obra como um custo passível de identificação com os clientes. Esse procedimento foi baseado no trabalho de Pereira (apud Catelli, 1999), que destaca que aos produtos/serviços devem ser associados todas as receitas e os custos variáveis necessários para gerá-los, desde que os custos sejam perfeitamente identificáveis. Pereira (apud Catelli, 1999, p. 215) conclui que "no nível de cada produto/serviço, devem ser confrontados os elementos que compõem a receita e custos gerados (materiais diretos, mão-de-obra)". 
A Tabela 10 demonstra a projeção do resultado sob a ótica do GECON.

\section{Tabela 10: Projeção do Resultado - Sistema GECON}

\begin{tabular}{|c|c|c|c|}
\hline DESCRIÇÃO & CLIENTE A & OUTROS CLIENTES & TOTAL \\
\hline \multicolumn{4}{|l|}{ ATIVIDADE FISCAL } \\
\hline Receita Operacional (1) & 400,00 & $2.000,00$ & $2.400,00$ \\
\hline Custo Mão-de-Obra Direta (2) & $(187,50)$ & $(812,50)$ & $(1.000,00)$ \\
\hline (I) Margem Operacional (1-2) & 212,50 & $1.187,50$ & $1.400,00$ \\
\hline Custos Fixos Identificados (3) & & & $(500,00)$ \\
\hline (II) Margem de Contribuição (1-2-3) & & & 900,00 \\
\hline \multicolumn{4}{|l|}{ ATIVIDADE PESSOAL } \\
\hline Receita Operacional (4) & 500,00 & $2.500,00$ & $3.000,00$ \\
\hline Custo Mão-de-Obra Direta (5) & $(312,50)$ & $(1.187,50)$ & $(1.500,00)$ \\
\hline (III) Margem Operacional (4-5) & 187,50 & $1.312,50$ & $1.500,00$ \\
\hline Custos Fixos Identificados (6) & & & $(500,00)$ \\
\hline (IV) Margem de Contribuição (4-5-6) & & & $1.000,00$ \\
\hline \multicolumn{4}{|l|}{ ATIVIDADE CONTABILIDADE } \\
\hline Receita Operacional (7) & $6.500,00$ & $30.000,00$ & $36.500,00$ \\
\hline $\begin{array}{l}\text { Custo Direto ( } 8 \text { ) } \\
\text { (mão-de-obra e preço de transferência) }\end{array}$ & $(1.462,50)$ & $(6.937,50)$ & $(8.400,00)$ \\
\hline (V) Margem Operacional (7-8) & $5.037,50$ & $23.062,50$ & $28.100,00$ \\
\hline Custos Fixos Identificados (9) & & & $(1.000,00)$ \\
\hline (VI) Margem de Contribuição (7-8-9) & & & $27.100,00$ \\
\hline $\begin{array}{l}\text { (VII) Margem de Contribuição dos Serviços } \\
(\mathrm{I}+\mathrm{III}+\mathrm{V})\end{array}$ & $5.437,50$ & $25.562,50$ & \\
\hline $\begin{array}{l}\text { (VIII) Margem de Contribuição Global } \\
\text { (II+IV+VI) }\end{array}$ & & & $29.000,00$ \\
\hline Custos Não Identificados (10) & & & $(20.000,00)$ \\
\hline Resultado Projetado (VIII-10) & & & $9.000,00$ \\
\hline
\end{tabular}

Cabe esclarecer que:

(1) Receita Operacional = menor preço no mercado à vista desta atividade, neste caso $\$ 400,00$.

(2) Custo de Mão-de-Obra Direta = gasto com funcionários da atividade fiscal $=\$ 187,50$ (vide Tabela 5).

(3) Custos Fixos da Atividade Fiscal = gasto com aluguel de software $=\$ 500,00$ (vide Tabela 1).

(4) Receita Operacional = menor preço no mercado à vista desta atividade, neste caso $\$ 500,00$.

(5) Custo de Mão-de-Obra Direta = gasto com funcionários da atividade pessoal $=\$ 312,50$ (vide Tabela 5). 
(6) Custos Fixos da Atividade Pessoal = gasto com aluguel de software = $\$ 500,00$ (vide Tabela 1 ).

(7) Receita Operacional $=$ valor do contrato fechado com o cliente, neste caso $\$ 6.500,00$.

(8) Custo Direto (MOD + Preço de Transferência) = preço de transferência das atividades fiscal e pessoal somado com os gastos com os funcionários da atividade contabilidade $(400,00+500,00+562,50=1.462,50)$.

(9) Custos Fixos da Atividade Contabilidade $=$ gasto com aluguel de software $=$ $\$ 1.000,00$ (vide Tabela 1).

(10) Custos não identificados = custos não identificados diretamente com as atividades de pessoal, fiscal e contabilidade. (Diretoria, Energia, Telefone, Material de Expediente, Aluguel do Escritório e Depreciação de Computadores) Custo não identificado = $15.000+1.000+700+800+1.000+1.500=20.000,00$.

E agora? Qual decisão deve ser tomada, já que pela análise do ABM o Cliente A apresenta um prejuízo de $\$ 810,25$ e a análise feita na ótica do GECON demonstra que o cliente possui uma margem de contribuição positiva de $\$ 5.437,50$ ?

Para esse tipo de análise pode-se utilizar o ABM estratégico que, segundo Kaplan e Cooper (1998, p.176), “opera alterando o mix de atividades, de modo a afastá-las de atividades mais lucrativas”. Assim, o ABM estratégico dá apoio a decisões sobre mix de produtos e seleção de clientes.

De acordo com Kaplan e Cooper (1998), analisando as margens líquidas e os custos na ótica do ABM, pode-se classificar os clientes da seguinte forma: (1) Clientes lucrativos: devem ser estabelecidas medidas de proteção, caso os concorrentes tentem fazer negócios; (2) Clientes não lucrativos: devem ser transformados em clientes lucrativos, melhorando os processos internos, negociando melhores relacionamentos no que se refere a pedidos e entregas, reduzindo descontos que não sejam associados à redução de custos e estabelecendo preços baseados em menus para serviços e recursos especiais. Neste exemplo a opção de negociar com o cliente melhores condições é a mais adequada; outra opção seria buscar novos clientes capazes de gerar uma boa lucratividade para empresa em substituição ao Cliente A.

Caso não haja possibilidade de aumentar a receita com esse cliente nem de substituí-lo, a utilização inadequada das informações geradas pelo ABM pode levar a empresa a tomar uma decisão errada. Se ela tomar a informação do custos gerada pelo ABM como sendo a do verdadeiro custo do cliente, e decidir 
não prestar mais serviços a ele, nem todos os custos atribuídos àquele cliente desaparecerão. Como resultado, o lucro da empresa será menor (Kaplan e Cooper, 1998). Na mesma linha de raciocínio, Atkinson et al. (2000) advertem que "a eliminação de produtos só ajudará a melhorar a rentabilidade se os gerentes (1) eliminarem os recursos de atividades não mais exigidos para apoiarem o produto descontinuado ou (2) transferirem os recursos desses produtos eliminados para produzir mais dos produtos lucrativos que a empresa continua oferecendo”.

$\mathrm{Na}$ análise por meio dos dados provenientes da projeção do resultado do GECON, podemos observar que o Cliente A possui uma margem de contribuição de $\$ 5.437,50$ e que os demais clientes possuem uma margem de contribuição de $\$ 25.562,50$, capaz de cobrir os custos fixos e indiretos, levando a concluir que a empresa já atingiu o ponto de equilíbrio (break-even point); ou seja, toda a margem de contribuição gerada pelo Cliente A vai direto para o lucro da empresa, reforçando a decisão de não abandoná-lo.

No entanto, esta análise também pode induzir a empresa a tomar uma decisão errada. Imaginemos agora que por usar apenas o GECON e acreditar que os diversos custos daquele cliente sejam os custos diretos, a empresa o classifique como bom e que deve ser mantido; sem saber que o cliente consome recursos fixos/indiretos, a empresa não fará nenhum esforço para substituí-lo.

Dessa simples análise pode-se dizer que nenhum dos dois métodos é completo. Cada um deles é adequado para um tipo de análise. Cada um deles produz um tipo de informação. Caberá ao responsável pela informação alertar o tomador de decisões sobre as restrições das informações geradas por cada um desses dois sistemas.

\section{Conclusão}

Da comparação entre os dois sistemas verifica-se que eles têm um grau elevado de convergência. Eles convergem em muitos pontos importantes. Ambos são sistemas gerenciais, têm o foco nas atividades, tratam as atividades como centro de resultados, usam o preço de transferência e empregam uma medida de lucro modificada para determinar o lucro econômico. Ainda que com alguma diferença quanto à intensidade, os dois sistemas têm um enfoque estratégico e operacional. Porém o GECON é mais focado nos aspectos operacionais do que o ABM, que é mais estratégico.

Ambos, GECON e ABM, têm como objetivo a busca da melhoria dos processos internos por meio do gerenciamento das atividades. O ABM, no 
entanto, está mais voltado para a cadeia de valor, enquanto o GECON tem como alvo principal a apuração do lucro econômico. Isto faz com que este se preocupe em discutir em maior detalhe uma série de critérios de avaliação dos aspectos econômicos, contábeis e financeiros que dão suporte ao seu modelo de mensuração.

O trabalho não buscou apontar qual sistema é melhor ou pior. Procurou-se apenas comparar os dois sistemas, para se conhecer o seu grau de convergência e em que aspectos eles são semelhantes ou divergentes. O entendimento é que, por definição, não existe modelo melhor do que o outro; existem situações que favorecem um sistema em detrimento do outro. Corroborando com essa afirmação, Martins (1998, p;314-315) explica que "é absolutamente incorreto dizer-se sempre que um método é, por definição, melhor do que outro. Na realidade, um é melhor que o outro em determinadas circunstâncias, para determinados fins [...] todos tem seus méritos e suas falhas [...] Se um deles fosse absolutamente correto e completo os outros já teriam desaparecido da literatura e da vida prática”.

\section{Nota}

${ }^{1}$ Este artigo recebeu menção honrosa no XXV ENANPAD.

\section{ReferÊnCIAS Bibliográficas}

ATTKINSON, A. A. et al.

Contabilidade gerencial. São Paulo: Atlas, 2000.

CATELLI, A. (Org.).

Controladoria: uma abordagem da gestão econômica. São Paulo: Atlas, 1999.

CATELLI, A.;

GUERREIRO, R.

GECON - gestão econômica: ad- ministração por resultados econômicos para otimização da eficácia empresarial. In: JORNADAS IBEROAMERICANAS DE COSTOS Y CONTABILIDAD DE GESTION; CONGRESSO ARGENTINO DE PROFESSORES UNIVERSITÁRIOS DE COSTOS, XVII., 1994, Trilio. Actas... [S.l.: s.n.], 1994. 
COOPER, R.;

KAPLAN, R. S.

The design of cost management systems. New Jersey: Prentice Hall, 1998.

\section{EHRBAR, A.}

EVA: valor econômico agregado - a verdadeira chave para a criação de riqueza. Rio de Janeiro: Qualitymark, 1999.

\section{GUERREIRO, R.}

Modelo conceitual de sistema de informação de gestão econômica: uma contribuição à teoria da comunicação da contabilidade. São Paulo,1989. Tese (Doutorado) - Faculdade de Economia, Administração e Contabilidade, Universidade de São Paulo.

KAPLAN, R. S.;

COOPER, R.

Custo e desempenho: administre seus custos para ser mais competitivo. São Paulo: Futura, 1998.

KAPLAN, R. S.;

NORTON, D. P.

Estratégia em ação: balanced scorecard. Rio de Janeiro: Campos, 1997.

\section{LIBONATI, J. J.}

Modelo gerencial de apuração de resultado para empresa agrícola: enfoque do sistema de gestão econômica - GECON. São Paulo, 1996. Dissertação (Mestrado) - Faculdade de Economia, Administração e Contabilidade, Universidade de São Paulo.

\section{MARTINS, E.}

Contabilidade de custos. 6. ed. São Paulo: Atlas, 1998.

\section{MASKELL, B. H.}

Making the number count: the accountant as change agent on the world class team. Portland: Productivity Press, 1996.

\section{RAFFISH, N.;}

TURNEY, P. B. B.

Glossary of activity-based management. Journal of Cost Management, v. 5, p. 53-63, 1991.

SAKURAI, M.

Gerenciamento integrado de custos. São Paulo: Atlas, 1997.

STEWART, G. B.

The quest for value: a guide for senior managers. New York: HarperCollins, 1991. 